\title{
Prognostic evaluation of febrile neutropaenia in apparently stable adult cancer patients
}

\author{
A Carmona-Bayonas*,', J Gómez ${ }^{2}$, E González-Billalabeitia', M Canteras ${ }^{3}$, A Navarrete ${ }^{4}$, ML Gonzálvez ${ }^{4}$, \\ V Vicente' and F Ayala de la Peña'
}

'Department of Haematology and Medical Oncology, University Hospital Morales Meseguer, Avda Marqués de los Vélez, S/n 3000I, Murcia, Spain; ${ }^{2}$ Department of Infectious Diseases, Hospital Virgen de la Arrixaca, Carretera de Madrid-Cartagena, S/n 30 I 20, Murcia, Spain; ${ }^{3}$ Department of Biostatistics, Faculty of Medicine, University of Murcia, Campus de Espinardo, 30 I00, Murcia, Spain; ${ }^{4}$ Department of Medical Oncology, Hospital Virgen de la Arrixaca, Carretera de Madrid-Cartagena, S/n 30120, Murcia, Spain

BACKGROUND: Predictive models to identify low-risk febrile neutropaenia (FN) have been developed with heterogeneous samples, which included stable and unstable patients, solid tumours, acute leukaemia and bone marrow transplantation. These models fail to recognise $5-15 \%$ of cases with unexpected complications, and literature specifically addressing apparently stable patients (ASPs) is scarce.

METHODS: We reviewed 86 I episodes of FN in outpatients with solid tumours, including 692 (80\%) episodes with apparent clinical stability. We aimed to investigate the prognosis of this latter group and explore the possibility of stratifying it according to the presenting features. A case-control study was performed and the MASCC index was evaluated.

RESULTS: The rates of complications and bacteraemia in ASPs were $7.3 \%$ and $6.2 \%$, respectively. The MASCC index yielded a low sensitivity to detect complications (36\%). Prognostic factors were identified: ECOG performance status $\geqslant 2$, chronic bronchitis, chronic heart failure, stomatitis $\mathrm{NCl}$ grade $\geqslant 2$, monocytes $<200 \mathrm{~mm}^{-3}$ and stress hyperglycaemia.

CONCLUSION: A very simple assessment is useful to classify the patients with FN according to the risk of complications. A few additional variables may predict the clinical course of the patients. We additionally show that the MASCC index applied to this specific group has a low sensitivity to predict complications.

British Journal of Cancer (201I) I 05, 612-617. doi:10.1038/bjc.201।.284 www.bjcancer.com

Published online 2 August 201I

(c) 201। Cancer Research UK

Keywords: febrile neutropaenia; apparently stable patients; prognostic model

Febrile neutropaenia (FN) is a common complication in cancer patients treated with chemotherapy. Although most of the cases are successfully solved with antibiotic treatment, a percentage of them can develop serious complications, and mortality is still significant in some settings (Sipsas et al, 2005). The prognostic models of Talcott and MASCC (see Table 1) were developed to predict the clinical outcome of patients with FN (Talcott et al, 1988; Klastersky et al, 2000). The latter model was validated several times and it is more accurate than Talcott's classification (Talcott et al, 1992; Uys et al, 2004). However, some problems still remain in the clinical setting. The derivation and validation of both models involved heterogeneous samples, with solid tumours, acute leukaemia and bone marrow transplantation (BMT), which differ in their baseline characteristics. Therefore, FN is managed differently in each particular scenario (Rossini et al, 1994; Nakagawa et al, 2009).

In the particular setting of Medical Oncology, the most common situations are moderate intensity chemotherapy, ambulatory setting, no profound immunosuppression and clinical stability at the onset (Talcott et al, 1988). In this situation, the rate of complications is around $9-15 \%$ according to the MASCC score

*Correspondence: Dr A Carmona-Bayonas; E-mail: alberto.carmonabayonas@gmail.com

Revised 31 May 20II; accepted 5 July 20II; published online 2 August 20II
(Klastersky et al, 2000, 2006). Although this group is less vulnerable, the introduction of home therapy and oral antibiotics can make the consequences of misclassification more relevant.

In addition, the patients enrolled in these studies showed a wide clinical spectrum, from fever without focus to multiorgan dysfunction (Talcott et al, 1988; Klastersky et al, 2000). As a result, the MASCC index includes some factors that define severe sepsis (Nguyen et al, 2006), even though they automatically point to high risk scenarios, thereby making the prediction irrelevant for changing medical decisions. Otherwise, the available literature regarding clinically stable patients is scarce (Moon and Chun, 2009). In this situation, there is also a rationale for incorporating biological variables into risk prediction (Jimeno et al, 2004; Uys et al, 2004). Therefore, it is still important to describe the clinical behaviour of more homogeneous samples of patients and, in particular, those who appear clinically stable at presentation. The primary aim of this study is to provide more data about the clinical features and prognosis of this specific population. The secondary objective is to explore the possibility of stratifying the group according to the presenting clinical features.

\section{PATIENTS AND METHODS}

\section{Patients}

The medical records of all adults ( $\geqslant 18$ years), outpatients, admitted between 1996 and 2004, with fever $\geqslant 38^{\circ} \mathrm{C}$ over $1 \mathrm{~h}$, 
Table I The MASCC index score

\begin{tabular}{lc}
\hline Category & Weight \\
\hline Burden of illness: no or mild symptoms & 5 \\
No hypotension & 5 \\
No chronic obstructive pulmonary disease & 4 \\
Solid tumour or no previous invasive fungal infection & 4 \\
Outpatient status & 3 \\
Burden of disease: moderate symptoms & 3 \\
No dehydration & 3 \\
Aged <60 years & 2 \\
\hline
\end{tabular}

Abbreviation: MASCC = Multinational Association of Supportive Care in Cancer. The maximum theoretical score is 26 . A MASCC score $\geqslant 21$ identifies low-risk patients with a positive predictive value of $91 \%$, specificity of $68 \%$ and sensitivity of $71 \%$ (Klastersky et al, 2000)

neutropaenia $\leqslant 500 \mathrm{~mm}^{-3}$ (or a count of $\leqslant 1000$ cells $\mathrm{mm}^{-3}$ with a predicted decrease to $\leqslant 500$ cells $\mathrm{mm}^{-3}$ ), chemotherapy and a solid tumour were reviewed. Patients treated with high-dose chemotherapy (HDC), including induction and intensification for acute leukaemia, BMT, the Magrath regimen and other induction treatments for Burkitt lymphoma, were excluded. The episode was considered valid if the management complied with current IDSA guidelines for FN (Hughes et al, 2002). Oral or ambulatory therapy was not offered. We additionally excluded the episodes in which $\geqslant 10 \%$ of the variables tested were missing. In case of multiple episodes for one patient, only the first one was evaluated. The study protocol was approved by the hospital investigational review board, and informed consent was obtained from patients.

\section{Study design}

Initial risk stratification We used objective criteria, such as the blood pressure, X-rays and blood tests, to classify the episodes into two categories: apparently stable patients (ASPs) and clearly unstable patients (CUPs). The CUP subgroup included those patients with any of these features at presentation: acute organ dysfunction, septic shock, hypotension, extensive infections (pneumonia, cellulitis $>5 \mathrm{~cm}$, typhlitis, meningitis and pyelonephritis) or any other acute comorbidity indicating hospital admission by itself. Patients without the attributes that characterised CUPs were considered ASPs. The medical records of the whole ASP group were reviewed to analyse the prevalence of complications that were not present at the diagnosis of FN, which comprised the triage and a basic workup (around $3 \mathrm{~h}$ ).

Potential risk factors in the ASP group We designed a retrospective case-control study. Both cases and controls were obtained from the same base (ASP group). A case was defined as a patient with an unexpected serious complication after admission. These events were defined according to the MASCC criterion (Klastersky et al, 2000). All cases were included in the analysis. In patients with multiple complications, we considered the most severe one to define the case. A control was defined as a randomly selected patient who was not a case. The whole ASP subgroup was analysed to calculate the prevalence of complications and to provide a completely randomised selection of controls. For the multivariate study, we planned a ratio of $1: 2$ for cases and controls, plus additional $25 \%$ controls to compensate missing values. No matching techniques were used. Selection of prognostic variables was performed after reviewing the literature and considering their availability in the Emergency Room setting. We also omitted the variables that were not accessible at the onset. Burden of disease was evaluated as in Klastersky et al (2000). Constitutional syndrome was defined as the presence of asthenia, anorexia and loss of $\geqslant 10 \%$ of body weight in the previous 3 months. As outlined in Table 2, most of the variables were dichotomic. For continuous variables, cutoffs were
Table 2 Variables tested as potential risk factors in febrile neutropaenia outcome

\begin{tabular}{|c|c|}
\hline Variables & Categories \\
\hline $\begin{array}{l}\text { Baseline characteristics and medical history } \\
\text { Age, years } \\
\text { Sex } \\
\text { Surgery in the previous month } \\
\text { ECOG performance status } \\
\text { Antibiotics in the previous month } \\
\text { Constitutional syndrome } \\
\text { COPD } \\
\text { Chronic heart failure } \\
\text { Diabetes mellitus } \\
\text { Lung cancer } \\
\text { Lymphoma } \\
\text { Breast cancer } \\
\text { TNM stage } \\
\text { Prophylactic GCSF } \\
\text { Adjuvant chemotherapy }\end{array}$ & $\begin{array}{l}\geqslant 65,<65 \\
\text { Male, female } \\
\text { Yes, no } \\
\geqslant 2,<2 \\
\text { Yes, no } \\
\text { Yes, no } \\
\text { Yes, no } \\
\text { Yes, no } \\
\text { Yes, no } \\
\text { Yes, no } \\
\text { Yes, no } \\
\text { Yes, no } \\
\text { IV, I-III } \\
\text { Yes, no } \\
\text { Yes, no }\end{array}$ \\
\hline 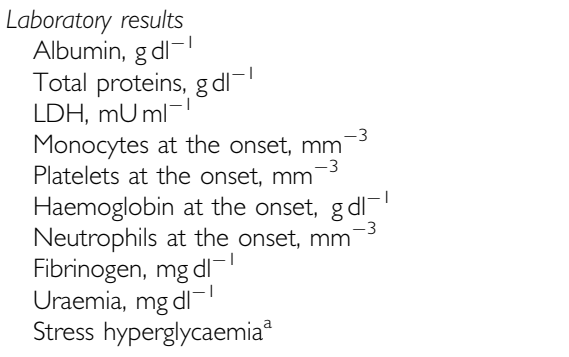 & $\begin{array}{l}<3, \geqslant 3 \\
<6.4, \geqslant 6.4 \\
\geqslant 475,<475 \\
<200, \geqslant 200 \\
<100000, \geqslant 100000 \\
\leqslant 9,>9 \\
\leqslant 100,>100 \\
\geqslant 450,<450 \\
\geqslant 30 \mathrm{mg},<30 \\
\quad \text { Yes, no }\end{array}$ \\
\hline $\begin{array}{l}\text { Characteristics of the febrile neutropaenia episode } \\
\text { Productive cough } \\
\text { Urinary infection } \\
\text { Fever of unknown origin } \\
\text { Abnormal X-ray without pneumonia at the onset } \\
\text { Heart rate } \geqslant 91 \\
\text { Respiratory rate } \geqslant 21 \\
\text { MASCC score } \\
\text { Burden of disease at the onset } \\
\text { Dehydration } \\
\text { Chills } \\
\text { Temperature at the onset, }{ }^{\circ} \mathrm{C} \\
\text { Stomatitis } \mathrm{NCl} \text { grade } \geqslant 2\end{array}$ & $\begin{array}{l}\text { Yes, no } \\
\text { Yes, no } \\
\text { Yes, no } \\
\text { Yes, no } \\
\text { Yes, no } \\
\text { Yes, no } \\
<21, \geqslant 21 \\
\text { Moderate, low } \\
\text { Yes, no } \\
\text { Yes, no } \\
\geqslant 39,<39 \\
\text { Yes, no }\end{array}$ \\
\hline
\end{tabular}

Abbreviations: $\mathrm{COPD}=$ chronic obstructive pulmonary disease; $\mathrm{ECOG}=$ Eastern Cooperative Oncology Group; GCSF=granulocyte-colony stimulating factor, $\mathrm{LDH}=$ lactate dehydrogenase; MASCC = Multinational Association of Supportive Care in Cancer, $\mathrm{NCl}=$ National Cancer Institute; TNM = tumour-node-metastasis. ${ }^{2}$ Stress hyperglycaemia: $\geqslant 121 \mathrm{mg} \mathrm{dl}^{-1}\left(\geqslant 250 \mathrm{mg} \mathrm{m}^{-2}\right.$ in diabetic patients).

defined according to previous reports (Groeger et al, 1998) or, when unavailable, to clinically relevant or NCI toxicity scale-based cutoffs.

\section{Statistical considerations}

For the univariate analysis, each potential risk factor was assessed using $\chi^{2}$-test or, when appropriate, Fisher exact test. Those variables with a $P$-value $<0.20$ were eligible for the multivariate analysis. The variables with $\geqslant 10 \%$ of missing values (chills, heart rate, respiratory rate and fibrinogen) were excluded. Clinical redundancy and potential overlapping was also a reason for exclusion. The covariates finally included in the stepwise logistic regression model were: age, sex, ECOG, constitutional syndrome, COPD, albumin, monocytes, platelets, uraemia, stress hyperglycaemia, productive cough, abnormal X-rays without pneumonia, stomatitis, chronic heart failure, burden of disease, lung cancer and breast cancer. Statistical analyses were carried out with the 
SPSS 15.0 software (SPSS Inc., Chicago, IL, USA). All test were twosided, and $P$-values $<0.05$ were considered significant.

\section{RESULTS}

The medical records of 861 valid episodes of FN were reviewed. We found that in 692 episodes $(80 \%)$, there were neither clinical findings of instability nor a serious infection at the onset. Hence, according to the medical record, we classified them as ASPs (Figure 1). The other 169 episodes (20\%) were classified as CUPs. The most frequent causes for classification as CUP were severe infections, but there were also complications unrelated to neutropaenia, such as embolism or arrhythmia. We analysed what happened with ASPs during the hospital admission. Only 51 patients $(7.3 \%)$ in the ASP group developed a serious complication, a rate in the range of low-risk MASCC group. The most frequent complications were acute respiratory failure (27 events), hypotension (25 events) and acute renal failure (11 events). Nine patients $(1.3 \%)$ died after admission and the cause of death was clearly related to infection in seven of them (1\%). Other complications were observed at a lower frequency (Table 3 ).

We observed a $6.2 \%$ rate of bacteraemia (43 episodes), which was lower than previously reported (Klastersky et al, 2007), a fact that we attributed to the selection of stable patients. We also found 22 cases (3.2\%) of delayed lung infiltrates. These categories showed some overlap: 14 patients with bacteraemia and 7 patients with delayed lung infiltrates had serious complications. The main features of the patients and the febrile episodes are shown in Table 4. To determine which prognostic factors were relevant in ASPs, a case-control study was designed.

We performed a univariate analysis as shown on Table 5 . The significant factors associated with complications were grouped in three categories: (1) baseline characteristics and comorbidity: age $\geqslant 65$ years, male, ECOG $\geqslant 2$, lung tumours, absence of breast cancer, COPD and chronic heart failure; (2) biological variables: albumin $<3 \mathrm{mg} \mathrm{dl}^{-1}$, proteins $<6.4 \mathrm{mg} \mathrm{dl}^{-1}$, uraemia $>30 \mathrm{mg} \mathrm{dl}^{-1}$, stress hyperglycaemia, monocytes $<200 \mathrm{~mm}^{-3}$ and platelets $<100000 \mathrm{~mm}^{-3}$; and (3) clinical characteristics of the febrile episode: stomatitis NCI grade $\geqslant 2$, productive cough, MASCC score $<21$ and constitutional syndrome. Interestingly, lung cancer showed an increased risk of complications (OR 3.43), mainly acute respiratory failure, whereas breast cancer was a protective factor (OR 0.34). In the multivariate analysis, six variables constituted independent risk factors: ECOG $\geqslant 2$, COPD, chronic heart failure, stomatitis grade $\geqslant 2$, monocytopenia and stress hyperglycaemia (Table 6).

The absence of a validation set precluded a head-to-head comparison between our model and MASCC, but we analysed the distribution of the MASCC scores in the cases and controls (Table 5). We observed that $85 \%$ of the sample had a MASCC index $\geqslant 21$. We calculated the following parameters to detect complications: sensitivity $36 \%$, specificity $94 \%$, positive predictive value $32 \%$, negative predictive value $94.9 \%$, positive likelihood ratio 6 ,

Table 3 Distribution of acute serious complications

\begin{tabular}{lc}
\hline Complication & $\mathbf{n}(\%)^{\mathbf{a}}$ \\
\hline Acute respiratory failure & $27(28)$ \\
Hypotension & $25(26)$ \\
Acute renal failure & $11(11)$ \\
Death & $9(9.5)$ \\
Altered mental status & $6(6.3)$ \\
Acute heart failure & $4(4.2)$ \\
Serious bleeding & $4(4.2)$ \\
Acute abdomen & $3(3.1)$ \\
Arrhythmia & $2(2.1)$ \\
Disseminated intravascular coagulation & $2(2.1)$ \\
Unstable angina & $1(1)$ \\
Total & 94 \\
\hline
\end{tabular}

${ }^{a}$ Number of complications. Multiples complications for one patient are shown here.

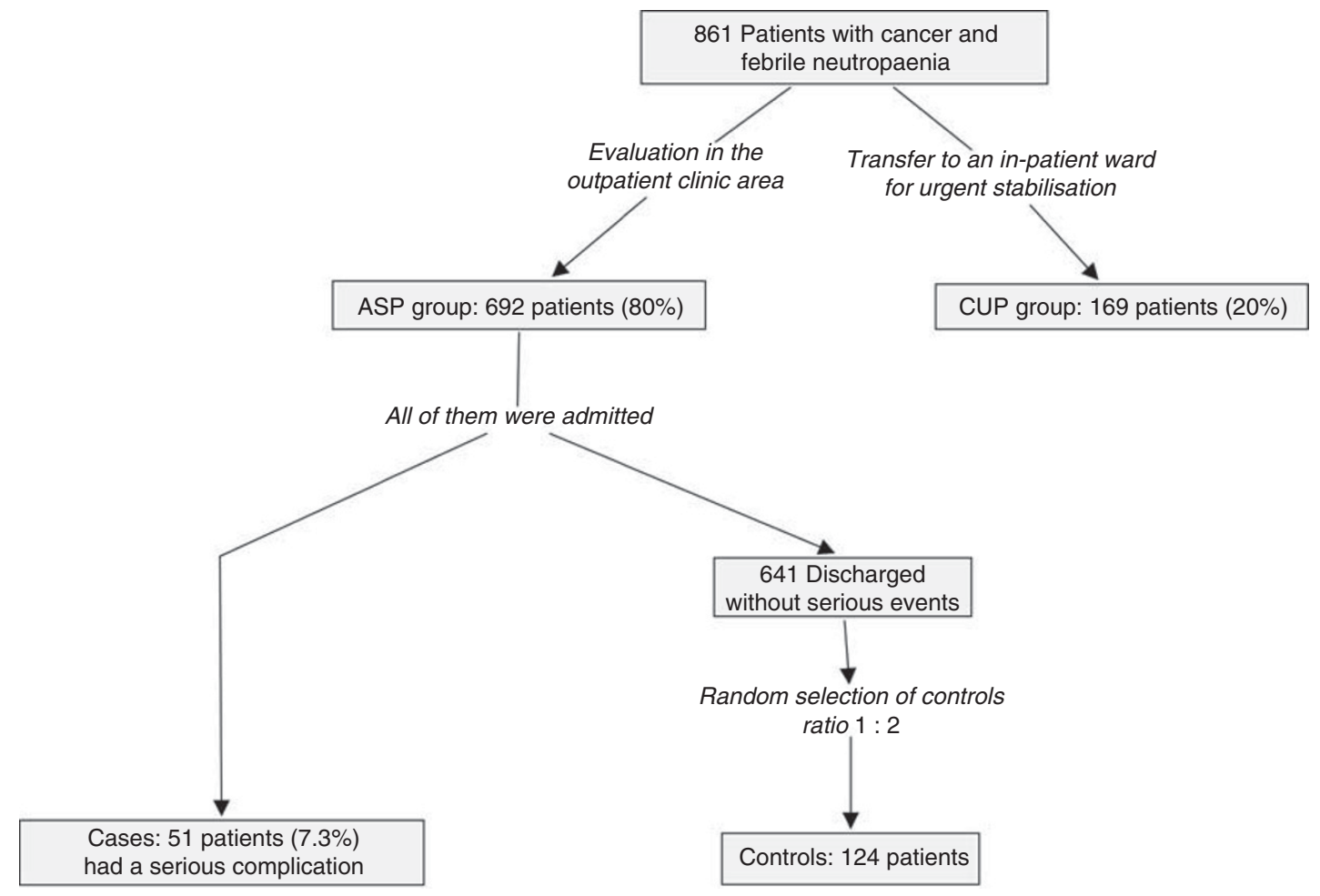

Figure I Flowchart summarising the study design. 
Table 4 Main features of the patients and the febrile episodes

\begin{tabular}{|c|c|}
\hline Characteristic & $N(\%)$ \\
\hline ECOG performance status $0-1$ & 138 (78) \\
\hline \multicolumn{2}{|l|}{ Tumours } \\
\hline Breast & $53(30)$ \\
\hline Lung & $41(23.4)$ \\
\hline Lymphoma & $31(18)$ \\
\hline Sarcoma & $13(7.5)$ \\
\hline Colorectal & $7(4)$ \\
\hline Other solid tumours & $30(17)$ \\
\hline \multicolumn{2}{|l|}{ Treatment setting } \\
\hline Adjuvant & $33(19)$ \\
\hline Neoadjuvant & $15(8)$ \\
\hline Advanced disease/palliative & $96(55)$ \\
\hline Other & $31(18)$ \\
\hline TNM stage IV & $96(55)$ \\
\hline MASCC $\geqslant 21$ & $144(85)$ \\
\hline \multicolumn{2}{|l|}{ Cause of the fever } \\
\hline Fever of unknown origin & $80(37)$ \\
\hline Clinically confirmed infection & $84(39)$ \\
\hline Microbiologically confirmed infection & $51(24)$ \\
\hline Days with neutropaenia $\leqslant 500 \mathrm{~mm}^{-3}$ & 3 (range I-8) \\
\hline Length of admission & 7.4 days \\
\hline Rate of unexpected complications & 7.3 \\
\hline Rate of bacteraemia & 6.2 \\
\hline Percentage of Gram negative in blood cultures & 65 \\
\hline Median age, years & 55 (range 13-85) \\
\hline
\end{tabular}

Abbreviation: ECOG = Eastern Cooperative Oncology Group.

negative likelihood ratio 0.6 and correct classification $89 \%$. The application of MASCC reduced the unexpected complications from 7.3 to $5.1 \%$. These calculations suggest a poor performance of the model in stable patients, as $64 \%$ of the cases with complications have a MASCC score $\geqslant 21$. When the variables included in the MASCC score were analysed, we found that no patient had hypotension or previous invasive fungal infection, the in-patient status was $0 \%$ and the rate of dehydration was $7 \%(n=13)$, as expected. The remaining three variables occurred relatively more often: COPD was present in $20 \%(n=35)$, moderate burden of disease in $39 \%$ and age $>60$ yeas in $42 \%(n=71)$.

\section{DISCUSSION}

Febrile neutropaenia is associated with significant morbidity and mortality in cancer patients. The MASCC index has been validated in the whole spectrum of $\mathrm{FN}$ and it is a precise tool for risk stratification (Klastersky et al, 2000). However, even in the lowrisk group, around $10 \%$ of patients develop serious complications (Klastersky et al, 2006).

Our study was designed from a pragmatic point of view. We hypothesised that our target population was considerably homogeneous and differed from the samples in which Talcott and MASCC models were developed. We excluded the cases with acute leukaemia, HDC and BMT, which selected for patients with an anticipated short duration of neutropaenia and a lower risk of complications. We also excluded in-patients because this prior status is considered a risk factor for complications according to MASCC and Talcott's models (Talcott et al, 1992). Moreover, an ultimate goal of prognostic models of low-risk FN is to identify a
Table 5 Predictive factors for serious complications in the univariate analysis

\begin{tabular}{|c|c|c|c|c|c|}
\hline Variables & $\begin{array}{l}\text { Cases, } \\
n(\%)\end{array}$ & $\begin{array}{c}\text { Controls, } \\
n(\%)\end{array}$ & OR & $95 \% \mathrm{Cl}$ & $P$-value \\
\hline \multicolumn{6}{|c|}{ Baseline characteristics and medical history } \\
\hline \multicolumn{6}{|c|}{ Age, years } \\
\hline$<65$ & $30(58.8)$ & $93(78.2)$ & 2.5 & $1.23-5.07$ & 0.010 \\
\hline$\geqslant 65$ & $21(41.2)$ & $26(21.8)$ & & & \\
\hline \multicolumn{6}{|l|}{ Sex } \\
\hline Female & $17(33.3)$ & $74(62.2)$ & 3.28 & $1.65-6.55$ & 0.001 \\
\hline Male & $34(66.7)$ & $45(37.8)$ & & & \\
\hline \multicolumn{6}{|c|}{ Surgery in the previous month } \\
\hline No & $47(92)$ & $108(88.5)$ & 0.6 & $0.2-2.1$ & 0.6 \\
\hline Yes & $4(8)$ & $14(1 \mid .5)$ & & & \\
\hline \multicolumn{6}{|c|}{ ECOG performance status } \\
\hline$<2$ & $32(62.7)$ & $106(89.1)$ & 4.84 & $2.1-10.86$ & $<0.0001$ \\
\hline$\geqslant 2$ & $19(37.3)$ & $13(10.9)$ & & & \\
\hline
\end{tabular}

Antibiotics in the previous month

\begin{tabular}{|c|c|c|c|c|c|}
\hline $\begin{array}{l}\text { No } \\
\text { Yes }\end{array}$ & $\begin{array}{l}32(62.7) \\
19(37.3)\end{array}$ & $\begin{array}{l}90(73.7) \\
32(26.3)\end{array}$ & 1.6 & $0.83-3.35$ & 0.14 \\
\hline \multicolumn{6}{|c|}{ onstitutional syndrome } \\
\hline No & $26(5 I)$ & $93(78.2)$ & 4.43 & $1.7-6.92$ & $<0.000$ I \\
\hline Yes & $25(49)$ & $26(21.8)$ & & & \\
\hline \multicolumn{6}{|c|}{ hronic bronchitis } \\
\hline No & $28(54.9)$ & $107(89.9)$ & 7.32 & $3.25-16.5$ & $<0.000$ \\
\hline Ype & $23(45.1)$ & $12(10.1)$ & & & \\
\hline
\end{tabular}

Chronic heart failure

$\begin{array}{lrcccc}\text { No } & 42(82.4) & 115(97.5) & 8.21 & 2.12-31.8 & <0.0001 \\ \text { Yes } & 9(17.6) & 3(2.5) & & & \end{array}$

Diabetes mellitus

$\begin{array}{llllll}\text { No } & 48(94.1) & 117(95) & 1.46 & 0.3-6.3 & 0.69\end{array}$

Yes $\quad 3(5.9) \quad 5(5)$

Lung cancer

$\begin{array}{llllll}\text { No } & 30(58.8) & 99(83.2) & 3.43 & 1.66-7.23 & 0.01\end{array}$

Yes $\quad 21(41.1) \quad 20(16.8)$

Breast cancer

$\begin{array}{llllll}\text { No } & 43(84.3) & 74(62.2) & 0.34 & 0.13-0.7 & 0.04\end{array}$

Lymphoma

$\begin{array}{llllll}\text { No } & 42(82.3) & 100(81.9) & 0.9 & 0.41-2.29 & 0.57\end{array}$

TNM stage

$\begin{array}{llllll}\text { I-III } & 20(39.2) & 59(48.3) & 1.45 & 0.7-2.8 & 0.3 \mid\end{array}$

IV $\quad 31(60.8) \quad 63(51.7)$

Prophylactic GCSF

$\begin{array}{llllll}\text { No } & 44(86.2) & 101(82.7) & 0.84 & 0.3-2.15 & 0.72\end{array}$

$\begin{array}{lll}\text { Yes } & 7(13.8) & 19(17.3)\end{array}$

Adjuvant chemotherapy

$\begin{array}{llllll}\text { No } & 43(84.3) & 95(77.8) & 0.65 & 0.2-1.55 & 0.4\end{array}$

$\begin{array}{lll}\text { Yes } & 8(15.7) \quad 27(22.2)\end{array}$

Laboratory results

Albumin, $\mathrm{mg} \mathrm{dl}^{-1}$

$\begin{array}{llllll}\geqslant 3 & 29(59.2) & 91(78.4) & 2.51 & 1.22-5.16 & 0.01 । \\ <3 & 20(40.8) & 25(21.6) & & & \\ & & & & & \\ \text { Total proteins, } \mathrm{mg} \mathrm{dl}^{-1} & & & & & \\ \geqslant 6.4 & 7(14.6) & 59(51.3) & 6.17 & 2.55-14.8 & <0.000 \text { । } \\ <6.4 & 41(85.4) & 56(58.7) & & & \end{array}$


Table 5 (Continued)

\begin{tabular}{|c|c|c|c|c|c|}
\hline Variables & $\begin{array}{l}\text { Cases, } \\
n(\%)\end{array}$ & $\begin{array}{c}\text { Controls, } \\
\text { n (\%) }\end{array}$ & OR & $95 \% \mathrm{Cl}$ & $P$-value \\
\hline \multicolumn{6}{|l|}{$\mathrm{LDH}, \mathrm{m} \cup \mathrm{ml}^{-1}$} \\
\hline $\begin{array}{l}<475 \\
\geq 475\end{array}$ & $30(58.9)$ & $81(66.3)$ & 1.42 & $0.7-2.9$ & 0.35 \\
\hline & & & & & \\
\hline \multicolumn{6}{|c|}{ Haemoglobin at the onset, $\mathrm{grdl}^{-1}$} \\
\hline$\geqslant 9$ & $39(76.4)$ & $102(83.6)$ & 1.6 & $0.7-3.7$ & 0.27 \\
\hline$<9$ & $12(23.6)$ & $19(16.4)$ & & & \\
\hline \multicolumn{6}{|c|}{ Neutrophils at the onset, $\mathrm{mm}^{-3}$} \\
\hline$\geqslant 100$ & $28(54.9)$ & $71(58.1)$ & 1.1 & $0.6-2.2$ & 0.73 \\
\hline$<100$ & $23(45.1)$ & $50(41.9)$ & & & \\
\hline \multicolumn{6}{|c|}{ Monocytes at the onset, $\mathrm{mm}^{-3}$} \\
\hline$\geqslant 200$ & $14(27.5)$ & $62(52.1)$ & 2.87 & $1.41-5.86$ & 0.003 \\
\hline$<200$ & $37(72.5)$ & $57(47.9)$ & & & \\
\hline \multicolumn{6}{|c|}{ Platelets at the onset, $\mathrm{mm}^{-3}$} \\
\hline$\geqslant 100000$ & $20(39.2)$ & $80(67.8)$ & 3.26 & $1.65-6.45$ & 0.001 \\
\hline$<100000$ & $31(60.8)$ & $38(32.2)$ & & & \\
\hline \multicolumn{6}{|c|}{ Uraemia, $\mathrm{mg} \mathrm{dl}^{-1}$} \\
\hline$\leqslant 30$ & $19(43.2)$ & $94(80.3)$ & 5.37 & $2.53-11.3$ & $<0.0001$ \\
\hline$>30$ & $25(56.8)$ & $23(19.7)$ & & & \\
\hline \multicolumn{6}{|c|}{ Stress hyperglycaemia ${ }^{a}$} \\
\hline No & $23(47.9)$ & $94(80.3)$ & 4.42 & $2.14-9.19$ & $<0.000$ । \\
\hline Yes & $25(52.1)$ & $23(19.7)$ & & & \\
\hline \multicolumn{6}{|c|}{ Characteristics of the febrile neutropaenia episode } \\
\hline \multicolumn{6}{|c|}{ Abnormal X-ray without pneumonia } \\
\hline No & $19(37.3)$ & $88(73.9)$ & 4.78 & $2.37-9.62$ & $<0.0001$ \\
\hline Yes & $32(62.7)$ & $31(26.1)$ & & & \\
\hline \multicolumn{6}{|c|}{ Stomatitis $\mathrm{NCl}$ grade } \\
\hline$<2$ & $31(60.8)$ & $94(79.7)$ & 2.52 & $1.23-5.18$ & 0.010 \\
\hline$\geqslant 2$ & $20(39.2)$ & $24(20.3)$ & & & \\
\hline \multicolumn{6}{|l|}{ MASCC } \\
\hline$\geqslant 21$ & $32(64)$ & $112(94)$ & 7.9 & $3-20.5$ & $<0.000$ । \\
\hline$<21$ & $18(36)$ & $7(6)$ & & & \\
\hline \multicolumn{6}{|c|}{ Urinary infection } \\
\hline No & $46(90.1)$ & $112(91.8)$ & 1.2 & $0.39-3.7$ & 0.7 \\
\hline Yes & $5(9.9)$ & $10(8.1)$ & & & \\
\hline \multicolumn{6}{|c|}{ Productive cough } \\
\hline No & $34(66.7)$ & || (94.1) & 7.92 & $3.03-20.7$ & $<0.000$ । \\
\hline Yes & $17(33.3)$ & $7(5.9)$ & & & \\
\hline \multicolumn{6}{|c|}{ Burden of disease } \\
\hline Low & $18(35)$ & $107(69)$ & 4.3 & $2.15-8$ & $<0.0001$ \\
\hline Moderate & $33(65)$ & $48(31)$ & & & \\
\hline
\end{tabular}

Abbreviations: $\mathrm{Cl}=$ confidence interval; $\mathrm{ECOG}=$ Eastern Cooperative Oncology Group; GCSF = granulocyte-colony stimulating factor; $\mathrm{LDH}=$ lactate dehydrogenase; $\mathrm{NCl}=$ National Cancer Institute; $\mathrm{OR}=$ odds ratio; $\mathrm{TNM}=$ tumour-node-metastasis. ${ }^{a}$ Stress hyperglycaemia: $\geqslant 121 \mathrm{mg} \mathrm{dl}^{-1}\left(\geqslant 250 \mathrm{mg} \mathrm{m}^{-2}\right.$ in diabetic patients).

group of patients that can be suitable for home treatment, thus making the inclusion of in-patients problematic.

We also reasoned that a prognostic model is more helpful to make meaningful decisions in non-obvious situations, such as the assessment of ASPs with subtle clinical signs. According to this clinically oriented approach, we classified our patients into two subgroups that we called ASPs and CUPs, and focused in the prognosis and traits of the former ones. The ASP subgroup
Table 6 Predictive factors for serious complications in the multivariate analysis

\begin{tabular}{llcc}
\hline Variable & OR & $\mathbf{9 5 \%} \mathbf{C l}$ & P-value \\
\hline ECOG, $\geqslant 2$ & 2.40 & $1.03-5.55$ & 0.041 \\
Chronic bronchitis & 4.45 & $1.95-10.17$ & $<0.0001$ \\
Chronic heart failure & 6.47 & $1.60-26.15$ & 0.009 \\
Stomatitis grade, $\geqslant 2$ & 2.59 & $1.15-5.81$ & 0.02 \\
Monocytes, $<200 \mathrm{~mm}^{-3}$ & 2.29 & $1.04-5.07$ & 0.04 \\
Stress hyperglycaemia & 3.06 & $1.43-6.54$ & 0.004 \\
\hline
\end{tabular}

Abbreviations: $\mathrm{Cl}=$ confidence interval; $\mathrm{ECOG}=$ Eastern Cooperative Oncology Group; OR = odds ratio.

represents $80 \%$ of our practice in a Medical Oncology unit. We report that this simple classification yields a rate of complications in the range of the MASCC low-risk group. Furthermore, we found that $85 \%$ of ASPs were MASCC $\geqslant 21$ (low risk), but this model had a lower sensitivity in our population than previously reported. This low performance was suggested by a $64 \%$ of patients with complications showing a MASCC index $\geqslant 21$. We interpreted this finding as a result of the selection, which defined a different sample to that in which MASCC was validated. The MASCC scale includes eight parameters, and the definition of low risk is a score $\geqslant 21$. But when we applied the model to our sample, the reason for the low sensitivity became clear. There are no in-patients, hypotension and invasive fungal infections and the rate of dehydration is low. As a result, these factors become useless to differentiate some cases from others. Only three factors are left to make a prognostic distinction. Although moderate burden of disease, COPD and age $>60$ years occur more often, they are still relatively infrequent, and thereby they are of limited discriminatory help.

For our second objective, a retrospective case - control study was considered, as complications are rare events in ASPs. For example, the MASCC Study included 1351 patients, but the derivation set only contained 32 low-risk patients with unexpected complications (Klastersky et al, 2000). Our aim is not to make a comparison with MASCC, but to assess the possibility to further stratify the ASP group, according to the presenting clinical features. Our hypothesis is that to reduce uncertainty we need to select not only more homogeneous samples but also to consider different types of variables. In fact, the study proposes that a combination of comorbidities, biological variables and toxicities might improve the prognostic evaluation.

The independent variables were ECOG $\geqslant 2$, COPD, chronic heart failure, stomatitis grade $\geqslant 2$, monocytes $<200 \mathrm{~mm}^{-3}$ and hyperglycaemia. These variables should not be adopted until further investigations could confirm the data and expose new sources of risk. However, all of them have a recognised biological substrate. Several studies have reported that a poor performance status is an adverse prognostic trait (Escalante et al, 1996; Sanz et al, 2002; Talcott et al, 2004; Klastersky et al, 2006). COPD is also a wellknown risk factor in $\mathrm{FN}$, as it is associated with serious bacterial infections and acute respiratory failure (Klastersky et al, 2000). The presence of stomatitis can predispose to bacteraemia (Bochud et al, 1994). Moreover, the inability to swallow is one of the causes that justify the hospitalisation (Rubenstein et al, 1993; Mullen et al, 1999; Talcott et al, 2004). Monocytopenia is linked with bacteraemia in children with FN (Rackoff et al, 1996), and early monocytopenia after chemotherapy is correlated with neutropaenia (Oguz et al, 2006). Finally, hyperglycaemia is common in critically ill patients, in which it is a well-known risk factor of complications (Dandona et al, 2003). Moreover, a randomised trial has shown that intensive insulin therapy reduces morbidity and mortality in this setting (Van den Berghe et al, 2001). We believe 
that the evaluation of biological variables is interesting in FN. Particularly, some reports have found that acute-phase reactants are useful as adjuvants to the clinical models (Kern et al, 2001; Nijhuis et al, 2005). Finally, our model has some other limitations beyond the requirement of validation. The selection of variables was based on easy availability, which excluded some potentially informative factors. Furthermore, all our patients were admitted to the hospital and received intravenous treatment, which might compromise the applicability of the model in the ambulatory setting.

As a conclusion, we have shown that a very simple assessment (ASP vs CUP) can classify cancer patients with FN according to the risk of complications. A few additional variables predict the clinical course of this population. Finally, the MASCC index applied to this specific group has a low sensitivity to predict complications.

\section{REFERENCES}

Bochud PY, Eggiman P, Calandra T, Van Melle G, Saghafi L, Francioli P (1994) Bacteremia due to viridans streptococcus in neutropenic patients with cancer: clinical spectrum and risk factors. Clin Infect Dis 18: 25-31

Dandona P, Aljada A, Bandyopadhyay A (2003) The potential therapeutic role of insulin in acute myocardial infarction in patients admitted to intensive care and in those with unspecified hyperglycemia. Diabetes Care 26: 516-519

Escalante CP, Rubenstein EB, Rolston KV (1996) Outpatient antibiotic treatment in low-risk febrile neutropenic cancer patients. Support Care Cancer 4: $358-363$

Groeger JS, Lemeshow S, Price K (1998) Multicenter outcome study of cancer patients admitted to the intensive care unit: a probability of mortality model. J Clin Oncol 16: $761-770$

Hughes WT, Armstrong D, Bodey GP (2002) Guidelines for the use of antimicrobial agents in neutropenic patients with cancer. Clin Infect Dis 34: $730-751$

Jimeno A, García-Velasco A, del Val O (2004) Assessment of procalcitonin as a diagnostic and prognostic marker in patients with solid tumors and febrile neutropenia. Cancer 100: 2462-2469

Kern WV, Heiss M, Steinbach G (2001) Prediction of gram-negative bacteremia in patients with cancer and febrile neutropenia by means of interleukin-8 levels in serum: targeting empirical monotherapy versus combination therapy. Clin Infect Dis 32: 832-835

Klastersky J, Ameye L, Maertens J (2007) Bacteraemia in febrile neutropenic cancer patients. Int J Antimicrob Agents 30: 51 - 59

Klastersky J, Paesmans M, Georgala A (2006) Outpatient oral antibiotics for febrile neutropenic cancer patients using a score predictive for complications. J Clin Oncol 24: 4129-4134

Klastersky J, Paesmans M, Rubenstein EB, Boyer M, Elting L, Feld R, Gallagher J, Herrstedt J, Rapoport B, Rolston K, Talcott J (2000) The multinational association for supportive care in cancer risk index: a multinational scoring system for identifying low-risk febrile neutropenic cancer patients. J Clin Oncol 18: 3038-3051

Moon JM, Chun BJ (2009) Predicting the complicated neutropenic fever in the emergency department. Emerg Med J 26: 802-806

Mullen CA, Petropoulos D, Roberts WM (1999) Outpatient treatment of fever and neutropenia for low risk pediatric cancer patients. Cancer 86: $126-134$

Nakagawa Y, Suzuki K, Masaoka T (2009) Evaluation of the risk factors for febrile neutropenia associated with hematological malignancy. J Infect Chemother 15: $174-179$
Nguyen HB, Emanuel PR, Fredrick MA (2006) Severe sepsis and septic shock: review of the literature and emergency department management guidelines. Ann Emerg Med 48: 54

Nijhuis CO, Kamps WA, Daenen SM (2005) Feasibility of withholding antibiotics in selected febrile neutropenic cancer patients. J Clin Oncol 23: $7437-7444$

Oguz A, Karadeniz C, Ckitak EC, Cil V (2006) Which one is a risk factor for chemotherapy-induced febrile neutropenia in childhood solid tumors: early lymphopenia or monocytopenia? Pediatr Hematol Oncol 23: $143-151$

Rackoff WR, Gonin R, Robinson C, Kreissman SG, Breitfeld PB (1996) Predicting the risk of bacteremia in children with fever and neutropenia. J Clin Oncol 14: 919-924

Rossini F, Pioltelli P, Mingozzi S (1994) Amikacin and ceftazidime as empirical antibiotic therapy in severely neutropenic patients: analysis of prognostic factors. Support Care Cancer 2: 259-265

Rubenstein EB, Rolston K, Escalante C (1993) Outpatient treatment of febrile episodes in low-risk neutropenic patients with cancer. Cancer 71: $3640-3646$

Sanz MA, López J, Lahuerta JJ (2002) Cefepime plus amikacin versus piperacillin-tazobactam plus amikacin for initial antibiotic therapy in haematology patients with febrile neutropenia: results of an open, randomized, multicentre trial. J Antimicrob Chemother 50: 79-88

Sipsas NV, Bodey GP, Kontoyiannis DP (2005) Perspectives for the management of febrile neutropenic patients with cancer in the $21 \mathrm{st}$ century. Cancer 103: 1103-1113

Talcott JA, Finberg R, Mayer RJ, Goldman L (1988) The medical course of cancer patients with fever and neutropenia: clinical identification of a low-risk subgroup at presentation. Arch Intern Med 148: 2561-2568

Talcott JA, Siegel RD, Finberg R, Goldman L (1992) Risk assessment in cancer patients with fever and neutropenia: a prospective, two-center validation of a prediction rule. J Clin Oncol 10: $316-322$

Talcott JA, Whalen A, Clark J, Rieker PP, Finberg R (2004) Home antibiotic therapy for low-risk cancer patients with fever and neutropenia: a pilot study of 30 patients based on a validated prediction rule. J Clin Oncol 12: $107-114$

Uys A, Rapoport BL, Anderson R (2004) Febrile neutropenia: a prospective study to validate the Multinational Association of Supportive Care of Cancer (MASCC) risk-index score. Support Care Cancer 12: 555-560

Van den Berghe G, Wouters P, Weekers F (2001) Intensive insulin therapy in critically ill patients. $N$ Engl J Med 345: 1359-1367

This work is published under the standard license to publish agreement. After 12 months the work will become freely available and the license terms will switch to a Creative Commons Attribution-NonCommercial-Share Alike 3.0 Unported License. 